\title{
Diffractive multifocal intraocular lens implants for unilateral cataracts in prepresbyopic patients
}

\author{
Peter J Gray, M G Lyall
}

\begin{abstract}
Multifocal intraocular lenses allow pseudophakic patients to obtain good near and distance visual acuities without an additional near correction. We report our experiences in implanting diffractive multifocal intraocular lenses in prepresbyopic patients with acquired unilateral cataracts and assess their postoperative visual acuities and stereoscopic vision. Accommodative function in patients following cataract surgery is discussed.
\end{abstract}

Extracapsular cataract extraction with the insertion of a posterior chamber intraocular lens is a safe and effective means of treating cataracts which provides an almost identical optical system to that of the human eye. But the pseudophakic eye is unable to accommodate because the intraocular lens is of a fixed power, and this necessitates a separate near addition. Clear vision for both distance and close work can, however, be offered to patients by inserting an intraocular lens with multifocal optics. These utilise the 'simultaneous vision principle' whereby separate images of near and distant objects are formed and, if the power difference between the two optical systems is at least 3.00 dioptres, the images are dissimilar enough for the brain to interpret them as separate, select the highly focused one relating to the object of regard, and suppress the other. This can be achieved with two distinct optical elements (the refractive or bull's eye type of multifocal intraocular lens) or by means of diffractive optics, ${ }^{1}$ where concentric diffractive zones are applied to the posterior surface of the implant in order to focus light from near objects.

We report our experiences in implanting a diffractive multifocal intraocular lens $(3 \mathrm{M}$ Vision Care) in prepresbyopic patients with acquired cataracts that have developed after the critical period for visual development.

\section{Patients and methods}

We report on a consecutive series of five prepresbyopic patients with acquired unilateral cataracts who received a diffractive multifocal intraocular implant between August 1989 and March 1990. Their clinical histories are detailed in Table 1. The patients, and parents if appropriate, were advised of the risks and benefits of the procedure, to which they accordingly gave informed consent. Preoperative biometry was performed in order to calculate the intraocular implant power. All of the cataract extractions were performed by a single experienced surgeon
(ML) under general anaesthesia using a standardised endocapsular technique. All of the operations were uncomplicated. Postoperatively the patients were reviewed until their pseudophakic vision had stabilised, at which time they were assessed with regard to unaided visual acuity in each eye for far, near, and intermediate objects (by reading a Snellen chart or reading test type at $10,15,30$, and $50 \mathrm{~cm}$ and 1 and $6 \mathrm{~m}$ ); the amplitude of clear vision (depth of focus) was measured for an N8 target; and the stereoscopic visual acuity was determined by means of the TNO or Titmus stereotests.

\section{Results}

The patient's stereoscopic visual acuity was classified into four grades: - grade 1 (less than 40 seconds of arc); grade 2 (40 to less than 60 seconds of arc); grade 3 (60 to 100 seconds of arc); and grade 4 (over 100 seconds of arc). These results and the patient's visual acuities with targets at various distances for both the pseudophakic eye and the normal accommodating eye are listed in Table 1. It should be noted that all these results are unaided, except for patient $C$, a myope, who used a contact lens and whose planned pseudophakic myopia was also corrected with a contact lens. The follow-up period varied from 12 to 18 months (mean 14 months).

In addition bilateral multifocal intraocular lenses were implanted asynchronously in a 27year-old woman with both Huntington's chorea and diabetes mellitus who developed acute diabetic cataracts. She unfortunately died 4 months after surgery but was able to spend her final weeks with clear distance vision (6/9) and clear near vision (N8) without the need for spectacles or contact lenses which would have been difficult in view of her neurological condition.

\section{Discussion}

Harold Ridley inserted the first intraocular lens with the intention of correcting the anisometropia of unilateral aphakia in order to restore binocular vision. ${ }^{2} \mathrm{He}$ realised that the pseudophakic eye was unable to accommodate, though the phenomenon of 'pseudoaccommodation', which is often between 2.00 and 4.00 dioptres, does occur, but only in a small number of cases. Thus the possibility of achieving Ridley's aim for the perfect restoration of binocular vision with the intraocular implant fulfilling all the physiological functions of the human lens has only recently been fully achieved with the introduction of multifocal intraocular lenses which can permit 
Table 1 Summary of results

\begin{tabular}{|c|c|c|c|c|c|c|c|c|c|c|}
\hline Patient & $A^{\star}$ & & $B^{\star}$ & & $C t$ & & $D$ & & $E$ & \\
\hline $\begin{array}{l}\text { Age at surgery } \\
\text { Eye }\end{array}$ & $\begin{array}{l}\text { 6years } \\
\text { Right }\end{array}$ & Left & $\begin{array}{l}16 \text { years } \\
\text { Right }\end{array}$ & Left & $\begin{array}{l}22 \text { years } \\
\text { Right }\end{array}$ & Left & $\begin{array}{l}25 \text { years } \\
\text { Right }\end{array}$ & Left & $\begin{array}{l}25 \text { years } \\
\text { Right }\end{array}$ & Left \\
\hline Ocular status & Normal & $\begin{array}{l}\text { Steroid-induced } \\
\text { cataract }\end{array}$ & $\begin{array}{l}\text { Perforating } \\
\text { injury }\end{array}$ & Normal & $\begin{array}{l}\text { Perforating } \\
\text { injury }\end{array}$ & Normal & $\begin{array}{l}\text { Perforating } \\
\text { injury }\end{array}$ & Normal & Normal & $\begin{array}{l}\text { Perforating } \\
\text { injury }\end{array}$ \\
\hline Preoperative visual acuit & y $6 / 6$ & $3 / 60$ & $<6 / 24$ & $6 / 4$ & $\mathrm{CF}$ & $\begin{array}{l}6 / 6 \\
(+\mathrm{CL})\end{array}$ & $\mathrm{CF}$ & $6 / 5$ & $4 / 4$ & $\mathrm{CF}$ \\
\hline \multicolumn{11}{|c|}{ Postoperative unaided acuities: } \\
\hline Snellen at $6 \mathrm{~m}$ & $6 / 6$ & $6 / 9$ & $6 / 5$ & $6 / 4$ & \multirow{7}{*}{$\begin{array}{l}6 / 6 \\
(+C L) \\
\text { N14 } \\
(+C L) \\
\text { N10 } \\
(+C L) \\
\text { N9 } \\
(+C L) \\
\text { N6 } \\
(+C L) \\
\text { N12 } \\
(+C L) \\
14-24\end{array}$} & \multirow{7}{*}{$\begin{array}{l}6 / 6 \\
(+\mathrm{CL}) \\
\mathrm{N} 10 \\
(+\mathrm{CL}) \\
\mathrm{N} 9 \\
(+\mathrm{CL}) \\
\mathrm{N} 8 \\
(+\mathrm{CL}) \\
\mathrm{N} 4 \cdot 5 \\
(+\mathrm{CL}) \\
\mathrm{N} 6 \\
(+\mathrm{CL}) \\
8-34\end{array}$} & $6 / 9$ & $6 / 5$ & $6 / 5$ & $6 / 9$ \\
\hline $\begin{array}{l}\text { Near vision test type at } \\
1 \mathrm{~m}\end{array}$ & $\mathrm{~N} 12$ & $\mathrm{~N} 24$ & $\mathrm{~N} 14$ & N8 & & & $\mathrm{N} 14$ & $\mathrm{~N} 10$ & N10 & $\mathrm{N} 12$ \\
\hline $\begin{array}{l}\text { Near vision test type at } \\
50 \mathrm{~cm}\end{array}$ & N10 & $\mathrm{N} 12$ & N10 & N6 & & & N10 & N8 & N9 & N10 \\
\hline $\begin{array}{l}\text { Near vision test type at } \\
30 \mathrm{~cm}\end{array}$ & N8 & N8 & N6 & $\begin{array}{l}\text { N5 } \\
(+C L)\end{array}$ & & & N8 & N6 & N6 & N8 \\
\hline $\begin{array}{l}\text { Near vision test type at } \\
15 \mathrm{~cm}\end{array}$ & N6 & N8 & N5 & $\mathrm{N} 4 \cdot 5$ & & & N6 & $\mathrm{N} 4 \cdot 5$ & N5 & N6 \\
\hline $\begin{array}{l}\text { Near vision test type at } \\
10 \mathrm{~cm}\end{array}$ & N10 & N10 & $\mathrm{N} 12$ & $\mathrm{~N} 10$ & & & N10 & $\mathrm{N} 12$ & N10 & $\mathrm{N} 12$ \\
\hline $\begin{array}{l}\text { Depth of focus for an } \\
\text { N8 target }(\mathrm{cm})\end{array}$ & $12-40$ & $14-32$ & $13-38$ & $15-55$ & & & $12-32$ & $14-54$ & $12-45$ & $10-33$ \\
\hline $\begin{array}{l}\text { Grade of stereoscopic } \\
\text { vision }\end{array}$ & \multicolumn{2}{|c|}{2} & \multicolumn{2}{|c|}{1} & \multicolumn{2}{|c|}{3} & \multicolumn{3}{|c|}{4} & 3 \\
\hline
\end{tabular}

^ Developed a posterior capsule opacity which required a Nd-YAG capsulotomy.

†All measurements were with a contact lens myopic correction.

binocular functioning for both close and distant vision without any additional spectacle correction.

The inability of the eye to accommodate after cataract surgery is of little handicap to the elderly patient who has been habituated to using a reading correction. However, this 'acquired presbyopia' will cause greater inconvenience to young patients accustomed to the process of accommodation. This will be more marked in unilateral cases, where there is little or no depth of focus in the pseudophakic eye yet normal accommodation in the dynamic fellow eye. These patients will have binocular vision for distance, yet be able to see clearly monocularly only for near. They are ideal candidates for multifocal intraocular lenses and become accustomed to the clear near vision of these implants more quickly than elderly patients (personal observations), whose brains have already 'forgotten' about intrinsic accommodative mechanisms and have been conditioned to use reading glasses for near vision.

Previous reports on multifocal intraocular lenses have compared the functioning of the multifocal intraocular lens with that of a monofocal intraocular lens in the fellow eye. This is the first study on multifocal intraocular lens function in younger patients with active accommodation in a phakic fellow eye. The reported series is small because, while it is comparatively easy to collect many patients with senile cataracts, cataracts in younger patients are much less common, and hence no statistical inferences can be made. However, all the patients obtained two peaks of clear vision, one at infinity (achieving at least $6 / 9$ ) and the other between 15 and $30 \mathrm{~cm}$, where they could read N8 or smaller, and most had stereoscopic vision. The diffractive multifocal implant therefore allowed these patients to correct all the optical problems of unilateral aphakia without the need for any spectacle correction. No patient specifically complained of any postoperative visual disturbance such as haloes, which have been described in some patients who have received multifocal intraocular lenses. ${ }^{3}$

Thus the diffractive multifocal intraocular lens has considerably improved the quality of life of all persons who received it. There has been much discussion $^{3}$ of the relative merits of implanting multifocal intraocular lenses, but the patients concerned have been elderly, with bilateral cataracts, and accustomed to using a reading correction prior to surgery. But this report concerns the advantages conferred by such lenses on prepresbyopic patients, who often have unilateral cataracts with normal accommodation in the fellow eye. Here the multifocal intraocular lens allows the pseudophakic eye to function in an integrated fashion with its fellow eye which has active accommodation.

We gratefully acknowledge the assistance given in the orthoptic assessment of these patients by Miss Jones and Miss Owen-Flood.

1 Simpson MJ. The diffractive multifocal intraocular lens. Eur $\mathcal{F}$ Implant Refract Surg 1989; 1: 115-21.

2 Ridley H. Intra-ocular acrylic lenses. Trans Ophthalmol Soc UK 1951; 71: 617-21.

3 Kaufman HE. Multifocal intraocular lenses - better or worse? Am $\mathcal{F}$ Ophthalmol 1990; 110: 424-5. 